\title{
Synthesis of aliphatic biodegradable polyesters nanoparticles as drug carrier for cancer treatment
}

\author{
Yasser Assem ${ }^{1 *}$, Fahima M Helaly ${ }^{1}$, AbdelMohsen Soliman $^{2}$, Sherein Abdelmoez ${ }^{3}$ \\ ${ }^{1}$ Polymers and Pigments Dept., National Research Centre, 33 Elbuhouth st., Dokki, Giza, Egypt. \\ ${ }^{2}$ Therapeutic Chemistry Dept., National Research Centre, 33 Elbuhouth st., Dokki, Giza, Egypt. \\ ${ }^{3}$ Microbiology and Immunology Dept., National Research Centre, 33 Elbuhouth st., Dokki, Giza, Egypt.
}

\begin{tabular}{|c|c|}
\hline ARTICLE INFO & ABSTRACT \\
\hline Article history: & \multirow{10}{*}{$\begin{array}{l}\text { New amphiphilic triblock copolymers of poly(hexylene adipates) (PHA) and methoxy poly(ethylene glycol) } \\
\text { (mPEG) having different hydrophobic/hydrophilic ratios were synthesized using a facile one-pot condensation } \\
\text { reaction. Three samples of three different molecular weights were synthesized and characterized using different } \\
\text { techniques. The synthesized copolymers were exploited to prepare core-shell nanoparticles with hydrophobic } \\
\text { PHA and hydrophilic mPEG forming the core and shell, respectively. The drug loading efficiency and drug } \\
\text { release properties of the mPEG-PHA-mPEG nanoparticles were investigated using 5-fluorouracil (5-FU) as a } \\
\text { drug model. The drug loading efficacy of the nanoparticles was found to be dependent upon the polymer } \\
\text { hydrophobicity. Drug release characteristics also depended on polymer hydrophobicity. The cytotoxicity of } \\
\text { released 5-FU was monitoring as an antiproliferative agent against human liver cancer cell line (HEPG2) as well } \\
\text { as antimicrobial against both gram-positive and gram-negative bacteria. Results of the in vitro cytotoxic activity } \\
\text { of the released 5-FU showed a sustained antiproliferative potency against the tested human liver cancer cell line } \\
\text { for } 26 \text { days. Besides, results of the antimicrobial study revealed that the most potent inhibitory activity was } \\
\text { against S. aureus which shows hindrance zone of about } 48 \text { mm against the tested reference strain. }\end{array}$} \\
\hline Received on: $22 / 09 / 2016$ & \\
\hline Revised on: 10/10/2016 & \\
\hline Accepted on: 01/11/2016 & \\
\hline Available online: $28 / 12 / 2016$ & \\
\hline Key words: & \\
\hline Block copolymers; & \\
\hline $\begin{array}{l}\text { nanoparticles; drug delivery; } \\
\text { polyester; controlled release; }\end{array}$ & \\
\hline $\begin{array}{l}\text { polyester; controlled release; } \\
\text { antitumor drugs. }\end{array}$ & \\
\hline & \\
\hline
\end{tabular}

\section{INTRODUCTION}

Development of biodegradable nanoparticles for effective protein, DNA, drug, and peptide delivery is an interesting research area that has been attracting much attention in the past few decades (Barratt et al., 2003). Loading of the drug onto a specially designed carrier has a lot of benefits, such as protection of the active substance against degradation in vivo and in-vitro, prolong its biological activity, the betterment of therapeutic effect, and control drug release rate (Couvreur et al., 2006; Rawat et al., 2013). One major downside of using nanoparticles as polymeric drug carriers is their rapid removal from the blood stream through phagocytosis after intravenous administration and recognition by the macrophages of the mononuclear phagocyte. Incorporation of the drug into a system

* Corresponding Author

Email: ya.assem@nrc.sci.eg,
(Stolnik et al., 19) keep the optimum level of the active constituent in the blood for extended time periods, long circulating polymer nanoparticles may be designed and utilized (Kataoka et al., 2001; Torchilin et al., 2002; Torchilin et al., 1995). PEGylation is the almost frequent method used to prepare amphiphilic polymeric nanoparticles with different characteristics (Orive et al., 2004; Owens et al., 2006; Gryparis et al., 2007). In this method, PEG is used as ahydrophilic segment that could be bonded to different hydrophobic segment. Examples of such hydrophobic segments are aliphatic polyesters. These polyesters are nowadays well known to be the most attractive and interesting materials to synthesize eco-friendly, biodegradable and biocompatible polymers (Dhamaniya et al., 2010; Winzenburg et al., 2004; Han et al., 2004). Poly(lactide) (PLA), poly(e-caprolactone) (PCL), poly(glycolide), (PGA), and poly (b-hydroxy butyrate) (PHB) are examples of such kind of polymers that have been potentially used as biodegradable and biocompatible polymers (Okada et al., 2002). 
Another interesting category of the aliphatic polyester is those derived from polycondensation of di-carboxylic acids and dihydric alcohols, for examples, Poly(butylene succinate) (PBS) has been synthesized through condensation polymerization of succinic acid and 1,4-butanediol, while Poly(butylene succinateco-adipate) (PBSA) is synthesized by polycondensation of succinic and adipic acids with 1,4-butanediol. Both have been commercialized under the trademark of BIONOLLE (Fujimaki et al., 1998) and used as a green polymer to replace the traditional nondegradable plastics in many final products. Depending on the dicarboxylic acid and dihydric alcohol used to synthesize the polyester, their physical, mechanical, thermal and crystal structure properties are greatly influenced (Yang et al., 2010; Ray et al., 2005). 5-FU is one of the most extensively used agents in cancer therapy. Its active form inhibits DNA synthesis by inhibiting the usual production of thymidine. It has a comparatively high response in the colon, rectal, breast, gastrointestinal tract pancreas, head, ovarian cancers (Sastre et al., 2007; Babu et al., 2006; Wang et al., 2005; Fournier et al., 2003). There are many studies in the literature for encapsulation of 5-FU in polymeric materials (Helaly et al., 2015; Helaly et al., 2014; Menei et al., 2004; Gudasi et al., 2006). These polymers ultimately experience hydrolytic scission, producing by- products that can be metabolized in the body. Polymers like gel (Jeyanthi et al., 1989), Chitosan (Huang et al., 2010), co- poly(D,L-lactic/glycolic acid (Gupte et al., 2004), poly(D-L-Lactide-co- glycolide) (Sastre et al., 2007) have been exploited in the controlled delivery of 5-FU.The aim of the present work deals to:

1. Reproduce the method of Vassiliou et al. (2010) to prepare triblock copolymer nanoparticles from polyethylene glycol and polyhexylene adipate with different molecular weights (mPEG-PHA-mPEG) and applied as a carrier for the anticancer drug 5-Fluorouracil (5-FU). The targeted copolymers will be of type ABA, where the A is $\mathrm{mPEG}$ and represents the hydrophilic segment and $\mathrm{B}$ is polyhexylene adipate PHA that represents the hydrophobic segment. The polymers can be self-assembled forming shoe horse like micelles with a shell of mPEG and a core of PHA.

2. Study the sustained release of 5-FU in different $\mathrm{pHs}$ and determine the loading and release efficiencies of the drug.

3. Determine the cytotoxic activity of the released 5fluorouracil against human liver cancer cell line as well as the antimicrobial potency against different bacteria strains namely $S$. aureus, E. coli and C. albicans.

\section{EXPERIMENTAL}

\section{Materials}

1,6-hexanediol was distilled before use $\left(160{ }^{\circ} \mathrm{C}\right.$ undervacuum). Adipic acid and Triton X100 were purchased from MerckGermany. Methoxypolyethylene glycol mPEG (Mn 5000 g/mol), Titanium (IV) Butoxide was purchased from SigmaAldrich and used as received. 5-FU was purchased from Aldrich. All solvents are supplied from either Sigma-Aldrich or Merck and distilled before use.

\section{Instrumentation and Characterization}

Fourier transform infrared (FTIR) were recorded using a Jascow FTIR-430 (Japan) Instrument. Proton nuclear magnetic resonance $\left({ }^{1} \mathrm{H} \mathrm{NMR}\right)$ was measured in $\mathrm{CDCl}_{3}$ using Jeol ECA 500 $\mathrm{MHz}$ NMR spectrometer. Gel permeation chromatography (GPC) was measured using Agilent 1100 series-Germany, Detector: Refractive Index. Eluent is $\mathrm{CHCl}_{3}$ using polyethylene oxide as a standard. High-resolution transmission electron microscopy images of polymeric nanoparticles were recorded by JEOL JEM 2100 T.E.M HR Japan. Thermogravimetric analysis (TGA) was conducted with Shimadzu TGA-50H. The measurements were performed at a heating rate of $10{ }^{\circ} \mathrm{C} \mathrm{min}{ }^{-1}$ from 30 to $800{ }^{\circ} \mathrm{C}$ under anitrogen atmosphere. Differential scanning calorimetry analysis (DSC) was recorded on Shimadzu DSC-60 differential scanning calorimeter Columbia, EUA. All samples were heated/cooled with a scan rate of $10{ }^{\circ} \mathrm{C} / \mathrm{min}$ over a temperature range of -100 to $100{ }^{\circ} \mathrm{C}$ under a nitrogen atmosphere. The particle size distribution of nanoparticles was determined by dynamic light scattering (DLS) using a Zeta-sizer Nano Instrument (Malvern Instruments, Nano ZS, ZEN3600, UK) operating with a $532 \mathrm{~nm}$. The distribution curves of samples 4-6 are shown in Fig 5.

\section{Synthesis of polyhexylene adipate (PHA) and (mPEG-PHA-b- mPEG) block copolymers.}

A typical experiment of synthesis of PHA is as follow: $24.9 \mathrm{~g}(0.17 \mathrm{~mol})$, of Adipic acid, $20.1 \mathrm{~g}(0.17 \mathrm{~mol})$ of 1,6 hexanediol were mixed together in a pre-evacuated $1 \mathrm{~L} \mathrm{~N}_{2}$-Flask under argon, then 0.05 mol \% of titanium IV-butoxide was added via $1 \mathrm{~mL}$ syringe. The system was connected to a condenser that ended with graduated Schlenk tube and placed in an oil bath at 170 ${ }^{\circ} \mathrm{C}$. The reaction continued under $\mathrm{N}_{2}$ until no more water was repelled out. At this point $0.1 \mathrm{~g} \%$ of Polyphosphoric acid was added via $1 \mathrm{~mL}$ syringe, $\mathrm{N}_{2}$ supply was removed and vacuum (1.0mbar) was applied and the reaction left to run for 2 hours at $220{ }^{\circ} \mathrm{C}$. At 0,60 and $120 \mathrm{~min}$ of vacuum application, samples were withdrawn from the reaction vessel in order to obtain PHA with different molecular weights. The samples were then reacted at 220 ${ }^{\circ} \mathrm{C}$ for $1 \mathrm{~h}$ under vacuum $(1.0 \mathrm{~Pa})$ with 3 quiv. of $\mathrm{mPEG}$ of molecular weight $5000 \mathrm{~g} / \mathrm{mol}$ using the same apparatus. The used amount of mPEG was calculated with respect to the carboxyl end groups of the used (Fras et al., 2002). The obtained viscous polymer is left to cool down and dissolved in THF or chloroform and precipitated in methanol/n-hexane mixture $1 / 10$. Dissolution/precipitation was repeated at least 3 times to remove the unreacted $\mathrm{mPEG}$.

\section{Preparation of drug-loaded nanoparticles}

The drug-loaded polymeric nanoparticles were prepared by dissolving $500 \mathrm{mg}$ of the copolymer and in $5 \mathrm{ml}$ 
dichloromethane and then added to $15 \mathrm{~mL}$ distilled water containing $0.1 \mathrm{~mL}$ triton $\mathrm{X}-100$ to form $\mathrm{O} / \mathrm{W}$ emulsion by using probe sonicator (300 watts, Sonic Vibro Cell, USA ) for 5 minutes. During this process, $50 \mathrm{mg}$ of 5-FU was added to the emulsion and again homogenized for 2 minutes. The formed $\mathrm{O} / \mathrm{W}$ emulsion was stirred gently until the evaporation of the organic solvent was completed. The nanoparticles were collected by centrifugation (5000 rpm for $20 \mathrm{~min}$ ).

The samples were reconstituted with deionized water. The suspension was filtered by a microfilter with apore size of 1.2 $\mu \mathrm{m}$ in order to remove polymer aggregates. To get the solid polymeric nanoparticles, the obtained micellar solutions were frozen and lyophilized in afreeze-drier. The weighed nanoparticles were dissolved in dichloromethane and the entrapped amount of 5FU was determined by UV spectrophotometer (Agilent Tech., Cary series, wavelength $255 \mathrm{~nm}$ ) and the nanoparticles yield, drug loading, and drug entrapment efficiency was calculated as described previously (Harisha et al., 2010; Papadimitriou et al., 2009).

Nanoparticles yield (\%)

$$
\begin{aligned}
& =\frac{\text { Weight of Nanoparticles }}{\text { weight of polymer and drug fed initially }} \\
& \times 100
\end{aligned}
$$

Drug loading (\%)

$$
=\frac{\text { weight of drug in nanoparticles }}{\text { weight of nanoparticles }} \times 100
$$

Entrapment efficiency (\%)

$$
=\frac{\text { weight of drug in nanoparticles }}{\text { weight of drug fed initially }} \times 100
$$

The invitro drug release studies were performed using dialysis method. Weighed amount of drug loaded nanoparticles (20 mg) were dispersed in the release medium, (3 different media were used at pHs, 7.4, 8.5 and 4.1) and placed in a dialysis cellulose membrane bag (Fischer Scientific), having a molecular weight cut-off 6000-80000, tied and placed into a closed vessel containing the dissolution media. The dissolution media are phosphate buffer solution $(0.1 \mathrm{M}, \mathrm{pH} 7.4)$, citrate buffer $(20 \mathrm{mM}$ $\mathrm{pH}$ 4.6) and borate buffer solution ( $\mathrm{pH} \mathrm{8.5).} \mathrm{The} \mathrm{whole} \mathrm{system}$ was placed in an incubator with anorbital shaker at $37{ }^{\circ} \mathrm{C}$. At predetermined time intervals $3 \mathrm{ml}$ of the aqueous solution was withdrawn from the release media and was replaced by fresh, medium. The samples were filtered and assayed for the drug by $\mathrm{UV}-\mathrm{V}$ is spectroscopy.

\section{Anticancer testing}

Measurement of potential cytotoxicity was done using SRB assay (Skehan et al., 1990). The timely released 5-FU was subjected to a screening system for evaluation of its antitumor activity against HepG2 liver cancer cell line.

\section{Antimicrobial testing}

Antibacterial activity of the time intervals released 5-FU was in vitro evaluated using agar well diffusion test (Sgouras et al., 2004;Wiart et al., 2007)against the following tested stains; Gram-negative bacterial reference strain; E. coli O157 ATCC 700728, Gram-positive bacterial reference stains; Strept. mutans ATCC 25175, Cl. perfringens ATCC 13124 and Enterotoxigenic S.aureus ATCC 13565, mycotic reference strain; $C$. albicans EMCC 105 As control positive Antibiotic $\left(\mathrm{AMC}_{30}\right)(30 \mu \mathrm{g} / \mathrm{ml})$ was used as standard antibacterial while Antimycotic $\left(\mathrm{AMB}_{30}\right)$ $(30 \mu \mathrm{g} / \mathrm{ml})$ was used as standard antifungi while dimethyl sulphoxide (DMSO) was used as control negative.

\section{RESULTS AND DISCUSSION}

\section{Synthesis and characterization of the block copolymers.}

The amphiphilic block copolymers (mPEG-PHA- $b$ $m P E G$ ) with different molecular weights were synthesized by polycondensation in one pot reaction over two steps. At first, carboxyl-terminated polyhexylene adipate (PHA) was obtained from the polycondensation of adipic acid and 1,6-hexanediol with very slight excess in the initial concentration of adipic acid in order to get carboxyl-terminated polyester.Sampleswere withdrawn at predetermined intervals to obtain PHA with different molecular weights. After that, polyethylene glycol monomethyl ether was condensed with the aforementioned samples for one hour under the same conditions to get three samples of the final block copolymer mPEG-b-PHA-b-mPEG (Scheme 1).

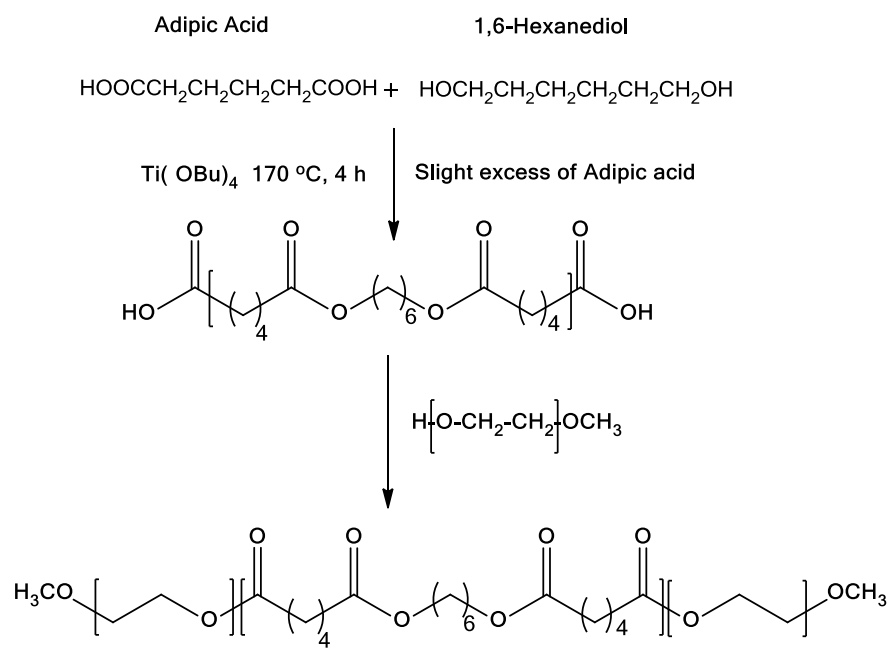

Scheme 1. Synthetic routeto synthesize mPEG-b-PHA-b-mPEG.

Molecular weights, polydispersity index, thermal analysis are presented in table (1). As can be seen from this table, the molecular weight of the homopolymers increases with the polymerization time. After only one hour of the condensation 
reaction, the Mn was $8700 \mathrm{~g} / \mathrm{mol}$ (sample 1, table 1). Further increase in the molecular weight was observed by continuing polycondensation when vacuum is applied at a higher temperature. The molecular weight was increased and jumped to be 15000 g/mol (sample 3, table 1). mPEG-PHA-mPEG triblock copolymers were synthesized by adding the monofunctional mPEG directly onto the melt polyester to condense with the carboxylic groups at both terminals.

Table 1: Molecular weight, conversion of the synthesized polymers.

\begin{tabular}{lcccll}
\hline Run & Time, $\mathbf{h}$ & $\begin{array}{c}\text { Mn, } \\
\text { g/mol }\end{array}$ & PDI & $\begin{array}{c}\text { Conversion, } \\
\mathbf{\%}\end{array}$ & $\begin{array}{c}\text { mPEG } \\
(\mathbf{m o l} \%)\end{array}$ \\
\hline \multicolumn{5}{l}{ Polyester homopolymers } \\
\hline 1 & 0.5 & 8700 & 3.04 & $\mathrm{n} / \mathrm{a}$ & $\mathrm{n} / \mathrm{a}$ \\
2 & 1.0 & 10000 & 2.00 & $\mathrm{n} / \mathrm{a}$ & $\mathrm{n} / \mathrm{a}$ \\
3 & 2.0 & 15000 & 1.97 & $\mathrm{n} / \mathrm{a}$ & $\mathrm{n} / \mathrm{a}$ \\
\hline \multicolumn{6}{l}{ Block Copolymers } \\
\hline 4 & 2.0 & 18000 & 2.02 & 87 & 77.5 \\
5 & 2.0 & 19600 & 1.85 & 85 & 50 \\
6 & 2.0 & 23500 & 2.16 & 85 & 35 \\
\hline
\end{tabular}

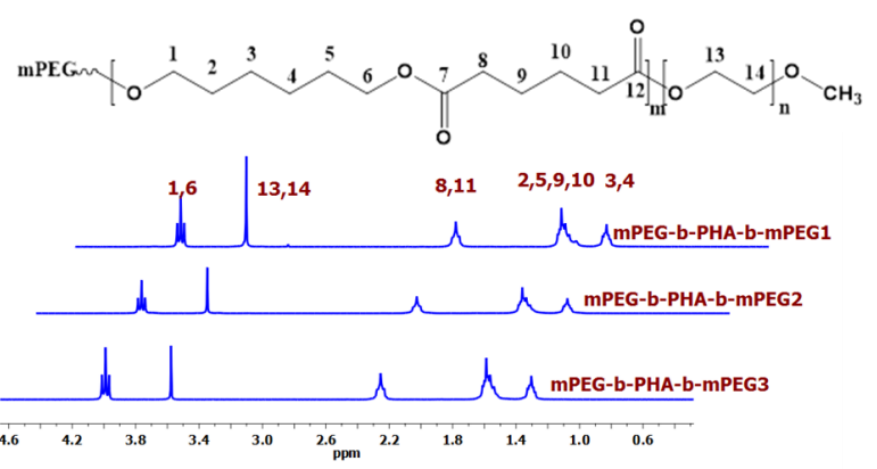

Fig. 1: ${ }^{1}$ HNMR of mPEG-b-PHA-b-MPEG.

In this method, we have made the homopolymer PHA terminated with $\mathrm{COOH}$ groups to ensure the direct condensation with the less reactive high molecular weight mPEG. According to the $\mathrm{Mn}$ values, the transesterification reaction is minimized. This was agreed with the results of Gallardo and Pişkin (Gallardo et al., 1998; Pişkin et al., 1995).This signposts that mPEG, with a molecular weight of $5000 \mathrm{~g} / \mathrm{mol}$, was mostly added to the macromolecules. Fig.(1) represents the GPC elugram of both homo and block-copolymers. The absence of any shoulder at the neat $\mathrm{mPEG}$ positions ensure that there was no significant amount of unreacted $\mathrm{mPEG}$ remain after the purification process in the copolymers. Fig. 2 shows the ${ }^{1} \mathrm{H}$ NMR spectrum of the prepared copolymers (mPEG-b-PHA-b-mPEG).

The peaks were assigned without any ambiguity according to that obtained by Kathrin et al(Sun et al., 2010). The peak at3.65 ppm was assigned to the methylene protons of the mPEG block $(13,14)$. The mPEG mole fraction in the polymers was calculated from the integrated peaks at $(13,14)$ to those of at $(1,6)$ ppm. It noted that the intensity of this methylene group of mPEG is decreased as the Mn of homo PHA is increased.

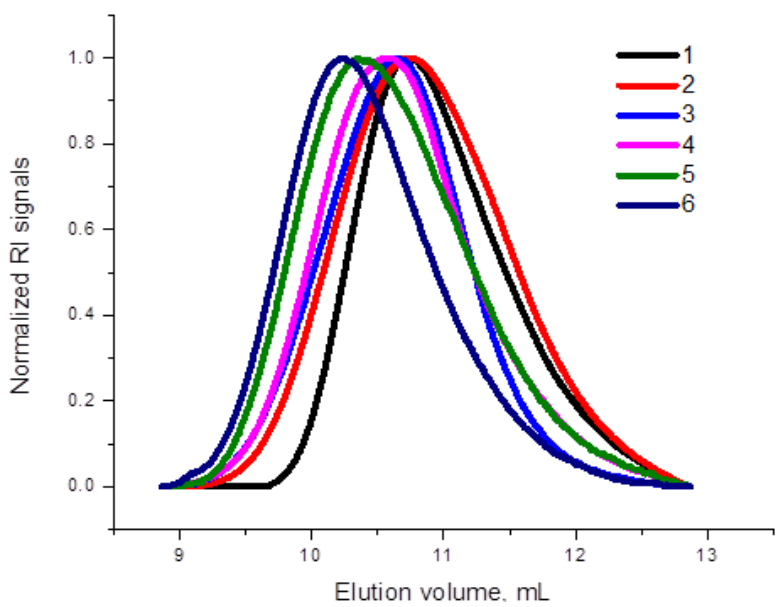

Fig. 2: GPC Elugrams of the synthesized polymers.

\section{Thermal Characterization}

The thermal stability of the synthesized block copolyesters was studied by DSC and TGA analysis and the curves are shown inFigs 3 and 4.The TGA curves in Fig 3 shows one-step degradation of the polymers. The polymers start to decompose at about $320{ }^{\circ} \mathrm{C}$ (0 \% decomposition) indicating a high thermal stability of the whole block copolymer categories. Temperatures at $0 \%$ and $5 \%$ decomposition are listed in table 2 .

Table 2: Decomposition temperature of homo and block copolymers at 0 and $\% 5$ decomposition.

\begin{tabular}{ccc}
\hline sample & $\mathbf{T}_{\mathbf{0} \%}{ }^{\mathbf{0}} \mathbf{C}$ & $\mathbf{T}_{\mathbf{5 \%}}{ }^{\mathbf{0}} \mathbf{C}$ \\
\hline 1 & 346 & 369 \\
2 & 319 & 372 \\
3 & 326 & 372 \\
4 & 324 & 358 \\
5 & 320 & 377 \\
6 & 326 & 367 \\
\hline
\end{tabular}

Thermal decomposition of linear aliphatic polyester gives at lower temperatures cyclic and linear esters or lactones, while at higher temperatures, further decomposition of the formed ester lead to give vinyl and carboxyl groups through ester scission and by cyclic elimination mechanism (Soccio et al., 2007). Plage et al. reported that the chain length of the diol subunits of polyesters plays the main role in the thermal decomposition of polyesters while the impact of the dicarboxylic acid one is less important (Plage et al., 1990). The melting behavior of the synthesized block copolyestersis studied using DSC measurements. The represented data in table 3, one can observe the melting point Tm of PHA homopolymers (samples 1 to 3 ) at $57{ }^{\circ} \mathrm{C}$, glass transition temperature of $-59{ }^{\circ} \mathrm{C}$ while the cold crystallization temperature Tcc appears at about $38{ }^{\circ} \mathrm{C}$. The heat of fusion $(\Delta \mathrm{Hm})$ values for all homopolymer samples are in the same range and the same to the block copolymer samples. No noticeable outcome of the chain length $(\mathrm{Mn})$ on all of these values. A slight lessening in melting point $\mathrm{Tm}$ from 57 to $54^{\circ} \mathrm{C}$ in the case of block copolymers was observed. Because of the akin values of Tm of both $\mathrm{MPEG}$ and PHA, a reunion of the two peaks could be possible during the heating cycle (Fig 4). Tg values form PEG were not perceived but 
it was reported in the literature at $-57{ }^{\circ} \mathrm{C}$ (Silva et al., 2007) nearly as those of PHA and also could interfere with those of PHA segments as also shown by Ferrutti et al. and Cohen et al. (Ferruti et al., 1995; Cohen, et al., 2000).

Table 3: Thermal data of the prepared block copolymers and homopolymers obtained from DSC measurements.

\begin{tabular}{ccccccccc}
\hline $\begin{array}{c}\text { MPEG/ } \\
\text { PE }\end{array}$ & \multicolumn{4}{c}{ mPEG segment } & \multicolumn{5}{c}{ PHA segment } \\
\hline & $\mathrm{Tg}$ & $\mathrm{Tm}$ & $\mathrm{Tcc}$ & $\Delta \mathrm{Hm}$ & $\mathrm{Tg}$ & $\mathrm{Tm}$ & $\mathrm{Tcc}$ & $\Delta \mathrm{Hm}$ \\
& ${ }^{\circ} \mathrm{C}$ & ${ }^{\circ} \mathrm{C}$ & ${ }^{\circ} \mathrm{C}$ & $\mathrm{J} / \mathrm{g}$ & ${ }^{\circ} \mathrm{C}$ & ${ }^{\circ} \mathrm{C}$ & ${ }^{\circ} \mathrm{C}$ & $\mathrm{J} / \mathrm{g}$ \\
\hline 1 & --- & --- & --- & --- & -59 & 57 & 37 & 81 \\
2 & --- & --- & --- & --- & -59 & 57 & 38 & 81 \\
3 & --- & --- & --- & --- & -60 & 58 & 38 & 81 \\
4 & --- & --- & 16 & --- & -58 & 55 & 37 & 63 \\
5 & --- & --- & 16 & --- & -56 & 54 & 36 & 65 \\
6 & --- & --- & 17 & --- & -58 & 55 & 38 & 65 \\
\hline
\end{tabular}

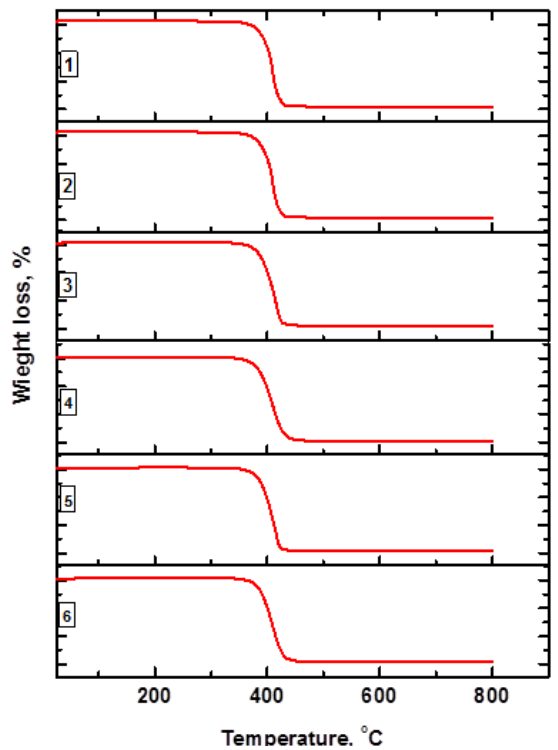

Fig. 3: TGA thermograms of the prepared block copolymers as well as the homopolymers

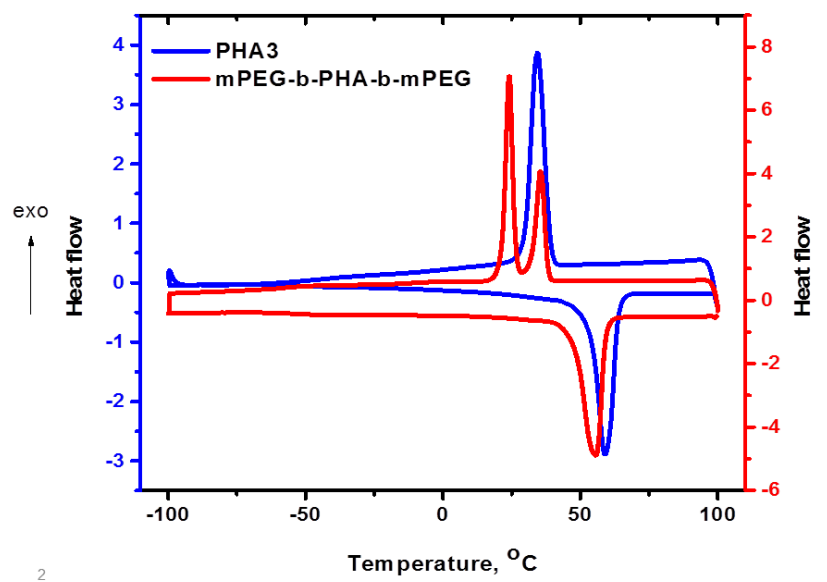

Fig. 4: DSC overlays of Heating and cooling cycles ofPHA andmPEG-PHA3b-mPEG (runs 3, 6, table 3).

The DSC thermograms of both heating and cooling cycles of mPEG-PHA-b-mPEG (run 3table 1)are shown in Fig 4, where the distinction between the two segments is observed in the cooling cycle and Tcc of both segments could be detected easily. The occurrence of two melting Tcc points designates a kind of phase separation between the two segments during the cooling cycle, however, a merging of the two melting is seen during the heating cycle because both segments have comparable melting points.

\section{TEM Characterization and size distribution of drug-loaded nanoparticles}

Due to the amphiphilic nature, the prepared polymers can form micelles in aqueous media, where the hydrophobic segment PHA is forming the core of the micelles while the two mPEG segments form the tail and directed to the water medium to give shoe horse-shaped micelles as represented in Fig. (5) (He et al., 2007). Table 4 shows the particle size distribution of the prepared drug-loaded mPEG-PHA-mPEG nanoparticles. The size of the nanoparticles varied between 164 to $190 \mathrm{~nm}$ with unimodal distribution, a small shoulder was appeared for the sample (6) with mean size of $530 \mathrm{~nm}$ but, it represents only $13 \%$ of the whole sample as shown in Fig 6. These results are consistent with other copolymers, where the longer the hydrophobic block, the bigger the micelles (Hu et al., 2007; Gaumet et al., 2008; Chen et al., 2006).

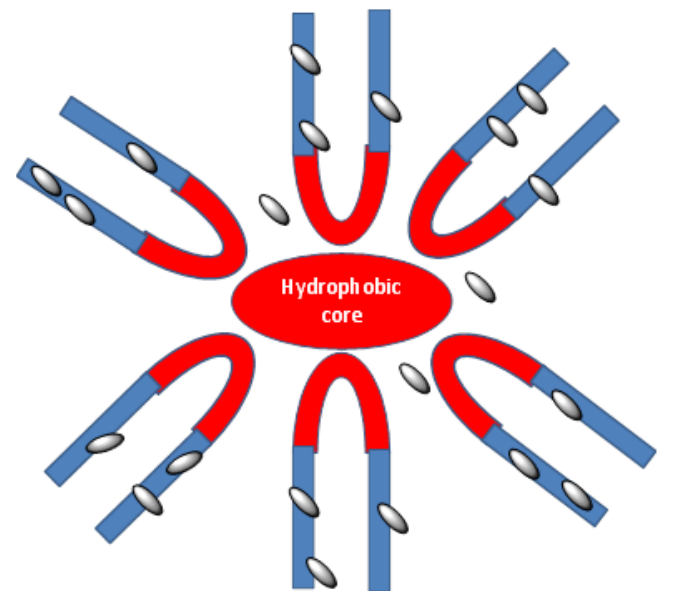

Fig. 5: A representative sketch showing the formation of mPEG-b-PHA-mPEG micelles

Table 4: Nanoparticle yield, drug loading content, entrapment efficiency, mean diameter and polydispersity index (PdI) of mPEG-bPHA-mPEG nanoparticles loaded with 5-FU.

\begin{tabular}{|c|c|c|c|c|c|c|}
\hline & 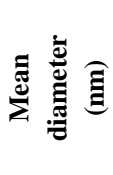 & $\overline{\mathbf{a}}$ & 吾 & 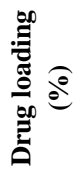 & 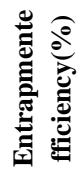 & 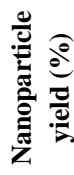 \\
\hline 4 & 164 & 0.151 & 87 & 7.3 & $\begin{array}{l}54.8 \\
\end{array}$ & 60.5 \\
\hline 5 & 164 & 0.145 & 77 & 7.9 & 53.4 & 61.1 \\
\hline 6 & 190 & 0.277 & 67 & 8.6 & 51.6 & 61.3 \\
\hline
\end{tabular}

A longer PHA block can boost its assembly to give larger core and, therefore, to a larger nanoparticle. Fig.6 shows representative TEM images of the prepared nanoparticles. All 
images show that most of the drug-loaded nanoparticles had a clear spherical shape in aqueous media, with a mean diameter less than $200 \mathrm{~nm}$, which is in agreement or even less with the results from the dynamic light scattering measurements. It is worthy to mention that the drug loading and drug entrapment efficiencies are slightly influenced by the length of the hydrophobic chain; there is a little increase in the drug loading capacity as the length of PHA increased. This may be referred to the corresponding increase in nanoparticle size.

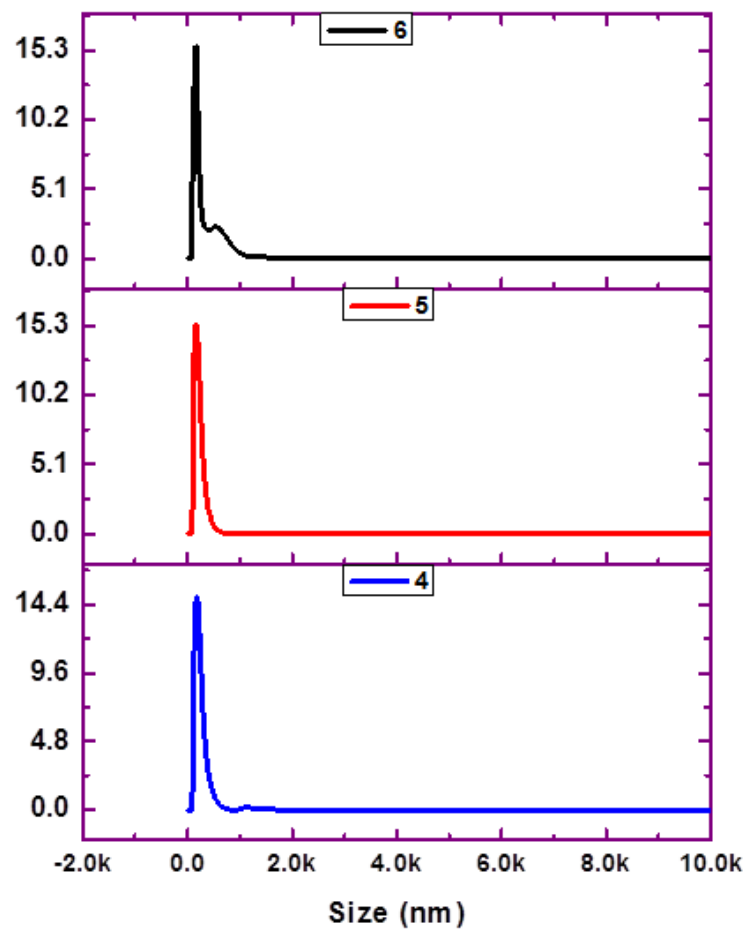

Fig. 6: Particle size distribution of the prepared nanoparticles.

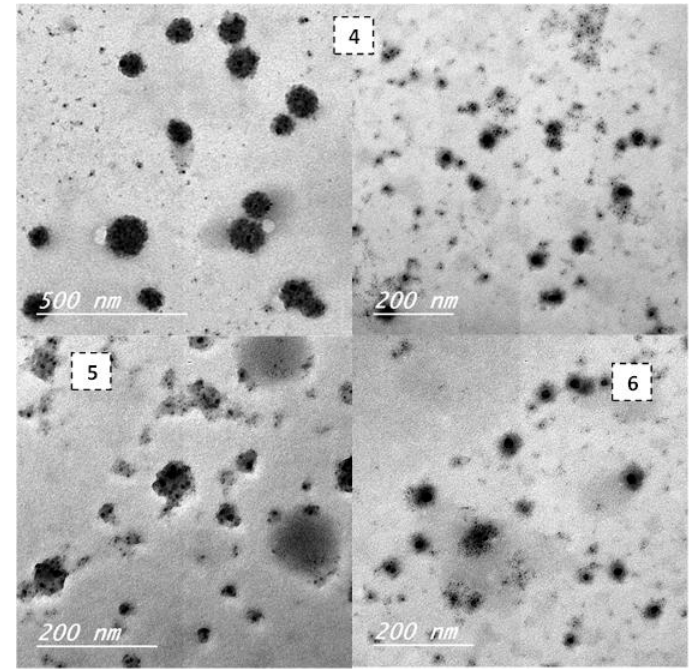

Fig. 7: TEM images of the prepared nanoparticles.

\section{Drug release behavior}

The release profiles of 5-FU form the prepared polymeric samples 4 to 6 in different $\mathrm{pH}$ media $(7.4,8.5,4.6)$ are represented in Figs. (8-11). A fast drug release was observed in the three media at early stages (until about $10 \mathrm{~h}$.) with nearly the same rate for the three samples, only slight increase in the release rate in case of sample 4 at $\mathrm{pH} 7.4$.

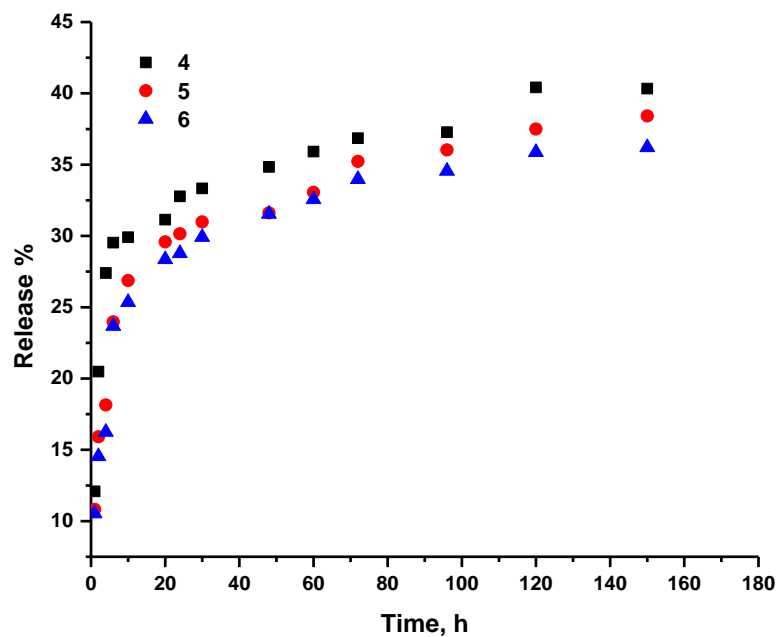

Fig. 8: Drug release profile for 5-FU from the prepared nanoparticles at $\mathrm{pH} 7.4$

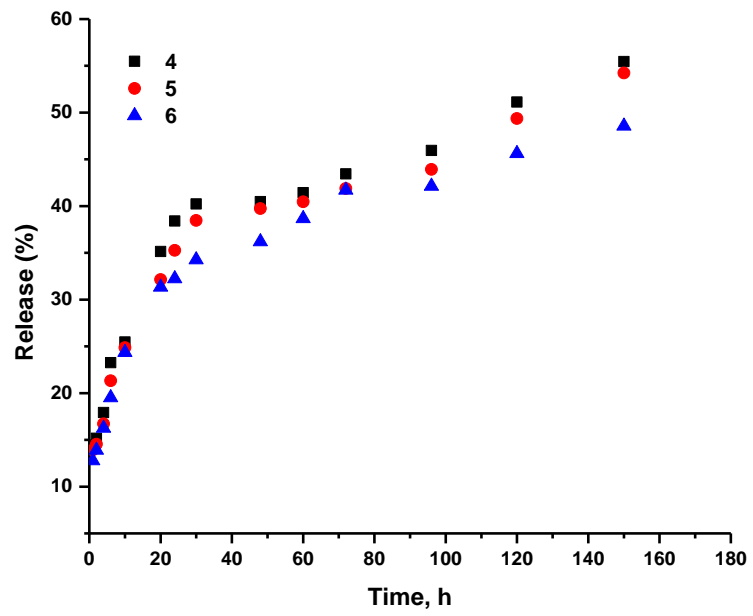

Fig. 9: Drug release profile for 5-FU from the three synthesized samples at $\mathrm{pH}$ 8.5 .

As the release time goes further, the rate of the release goes slower at all $\mathrm{pH}$ media and for all molecular weights. It was also observed that the overall release rate of all samples was higher at $\mathrm{pH}$ (4.6 and 8.5), i.e. in both acidic and alkaline media. It was stated that more than one factor can influence the control release process of any drug from polymeric carriers. Instances of these factors are; degradation rate of the polymeric carriers, crystallinity, molecular weight, melting behavior, glass transition temperature, mode of crystallization, the ability of the drug to bind to the polymer, loading efficacy, etc. (Gref et al., 1994;Zhang et $a l ., 2004)$. So the burst release at the beginning is expected to be due to a fraction of drug particles near to or on the surface of the 
nanoparticles as also reported by Ge et al. (Ge et al., 2002). Regarding the effect of $\mathrm{pH}$ on the release rate, it is also expected that the rate is increased in both acidic and alkaline media, due to the effect of hydrolysis of the hydrophobic moiety PHA leading to a fast release form the hydrolyzed residue (Assem, 2011) as shown in Fig.11. The effect of chain length on the release process is also observed. It is clearly seen from Figs 8-10 that sample 3 that possesses the lowest molecular weight is always giving a higher release rate than the others.

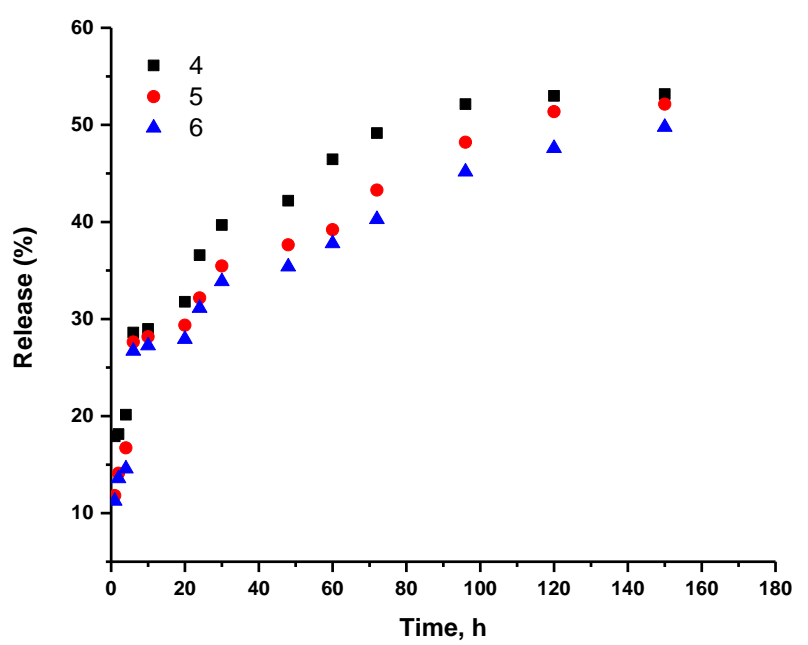

Fig. 10: Drug release profile for 5-FU from the three synthesized samples at pH 4.6

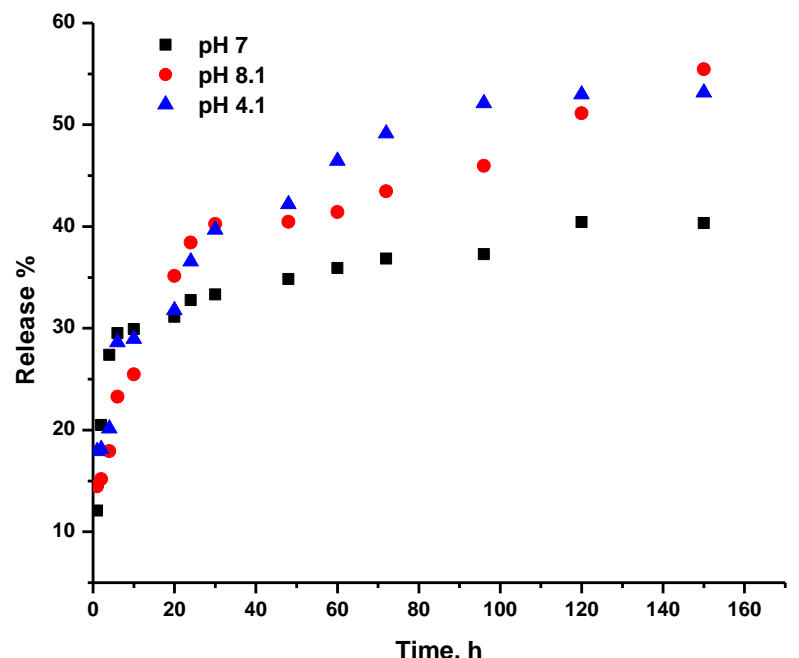

Fig. 11: Effect of pH on drug release rate for 5-FU from sample No 4 Table 1.

\section{BIOLOGICAL RESULTS}

\section{Effect of released 5FU on Liver cancer cell line}

It is interesting to evaluate the released 5-FU from the prepared polymeric nanoparticles on the human liver cancer cell line. Table (5) and Fig.(12) show the results obtained from the practical experiment on human liver cell line HEPG2. It was found that promising results were obtained, the inhibition percent was extended to about 14 days.

Table 5: Single dose on HEPG2 cell-line $(100 \mu \mathrm{g} / \mathrm{ml})$ 5-fluorouracil Released from mPEG-PHA-mPEG (Sample 4).

\begin{tabular}{ccccc}
\hline $\begin{array}{c}\text { Released } \\
\text { Samples }\end{array}$ & $\begin{array}{c}\text { Concentration, } \\
\text { mM }\end{array}$ & Time, $\mathbf{h}$ & $\begin{array}{c}\text { Surviving, } \\
\mathbf{\%}\end{array}$ & $\begin{array}{c}\text { Inhibition, } \\
\mathbf{\%}\end{array}$ \\
\hline 1 & 0.04 & 1 & 63.2 & 36.9 \\
2 & 0.07 & 2 & 57.8 & 42.2 \\
3 & 0.09 & 4 & 65.9 & 34.1 \\
4 & 0.10 & 6 & 68.7 & 31.3 \\
5 & 0.11 & 10 & 69.5 & 30.5 \\
6 & 0.11 & 20 & 71.5 & 28.5 \\
7 & 0.12 & 24 & 64.7 & 35.3 \\
8 & 0.12 & 30 & 73.1 & 26.9 \\
9 & 0.12 & 48 & 66.3 & 33.7 \\
10 & 0.13 & 60 & 65.5 & 34.5 \\
11 & 0.13 & 72 & 87.9 & 12.1 \\
12 & 0.13 & 96 & 72.3 & 27.7 \\
13 & 0.14 & 120 & 76.3 & 23.7 \\
14 & 0.14 & 150 & 72.3 & 27.7 \\
\hline
\end{tabular}

\section{Antimicrobial effect of released 5FU on gram positive and gram negative bacteria}

The released 5-FU was tested against different bacteria strains namely $S$. aureus, E. coli and C. albicans. Table 6 and Fig. 12 indicated that the best results were shown against $S$. aureus using the drug released from 1 to 14 which show great hindrance against the tested enterotoxigenic reference strain ( $S$. aureus).

Table 6: Antimicrobial activity of 5- fluorouracil released from mPEG-b-PHAmPEG (Sample 4).

\begin{tabular}{|c|c|c|c|c|c|}
\hline \multirow{2}{*}{$\begin{array}{l}\text { Released } \\
\text { Samples }\end{array}$} & \multirow{2}{*}{$\begin{array}{c}\text { Concentration } \\
, \mathrm{mM}\end{array}$} & \multirow{2}{*}{$\begin{array}{c}\text { Time, } \\
\text { h }\end{array}$} & \multicolumn{3}{|c|}{ Zone diameter,mm for } \\
\hline & & & E. coli & S.aureus & C. albicans \\
\hline \multicolumn{6}{|c|}{ PLATE1 } \\
\hline 1 & 0.0423 & 1 & $10 \mathrm{~S}$ & 34 & $-\mathrm{VE}$ \\
\hline 2 & 0.0717 & 2 & $\mathrm{~S}$ & 31 & $-\mathrm{VE}$ \\
\hline 3 & 0.0959 & 4 & 13 & 33 & $-\mathrm{VE}$ \\
\hline 4 & 0.1033 & 6 & $-\mathrm{VE}$ & 28 & $-\mathrm{VE}$ \\
\hline 5 & 0.1047 & 10 & 15 & 30 & $-\mathrm{VE}$ \\
\hline 6 & 0.1090 & 20 & 12 & 32 & $-\mathrm{VE}$ \\
\hline \multicolumn{6}{|c|}{ PLATE 2} \\
\hline 7 & 0.1147 & 24 & 14 & 34 & $-\mathrm{VE}$ \\
\hline 8 & 0.1167 & 30 & $12 \mathrm{~S}$ & 34 & $-\mathrm{VE}$ \\
\hline 9 & 0.1219 & 48 & $-\mathrm{VE}$ & 42 & $-\mathrm{VE}$ \\
\hline 10 & 0.1257 & 60 & $12 \mathrm{~S}$ & 38 & $-\mathrm{VE}$ \\
\hline 11 & 0.1290 & 72 & $-\mathrm{VE}$ & $-V E$ & $-\mathrm{VE}$ \\
\hline 12 & 0.1305 & 96 & 15 & 34 & $-\mathrm{VE}$ \\
\hline \multicolumn{6}{|c|}{ PLATE 3} \\
\hline 13 & 0.1415 & 120 & 16 & 33 & $-\mathrm{VE}$ \\
\hline 14 & 0.1412 & 150 & $-V E$ & 32 & $-V E$ \\
\hline DMSO & & & $-V E$ & $-V E$ & $-V E$ \\
\hline $\begin{array}{l}\text { ANTIBIO } \\
\text { /ANTIMY }\end{array}$ & $\begin{array}{l}\mathrm{C}\left(\mathrm{AMC}_{30}\right) \\
\mathrm{OTIC}\left(\mathrm{AMB}_{30}\right)\end{array}$ & & 17 & 12 & 26 \\
\hline
\end{tabular}

The best effect was no 9 and 10 with the zone of inhibition equals 42 and $38 \mathrm{~mm}$, respectively, followed by release no $1,7,8$ and 12 with zone of inhibition equals $34 \mathrm{~mm}$ then compounds 3, 13 and 15 with zone of inhibition $33 \mathrm{~mm}$ then compounds 6 and 14 with the zone of inhibition equals $32 \mathrm{~mm}$ and the least hindrance was with release 2 and 5 with the zone of inhibition 31 and $30 \mathrm{~mm}$. The tested compounds were more effective against $S$. aureus is more than the reference drug AMC 
$30 \mu \mathrm{g} / \mathrm{ml}$ which shows hindrance zone of $12-13 \mathrm{~mm}$ against the tested ref strain. On the contrary, the tested compounds didn't show any hindrance abilities against the tested mycotic reference stain; C. albicans EMCC105. Although the reference drug AMB $30 \mu \mathrm{g} / \mathrm{ml}$ gives azone of inhibition equals $26-30 \mathrm{~mm}$.

Few compounds were effective against tested reference E. coli 0157 ATCC 700728as shown with samples no 13 and samples no5, 12 with the zone of inhibition equal $16 \mathrm{~mm}$ and $15 \mathrm{~mm}$ respectively. Followed by samples no 7,3 and 6 with the zone of inhibition equal 14,13 and 12 respectively. On the other hand, few compounds show the bacteriostatic effect of compounds no 8,10 and 1 with zone of bacteriostatic equals 12 and $10 \mathrm{~mm}$, respectively.
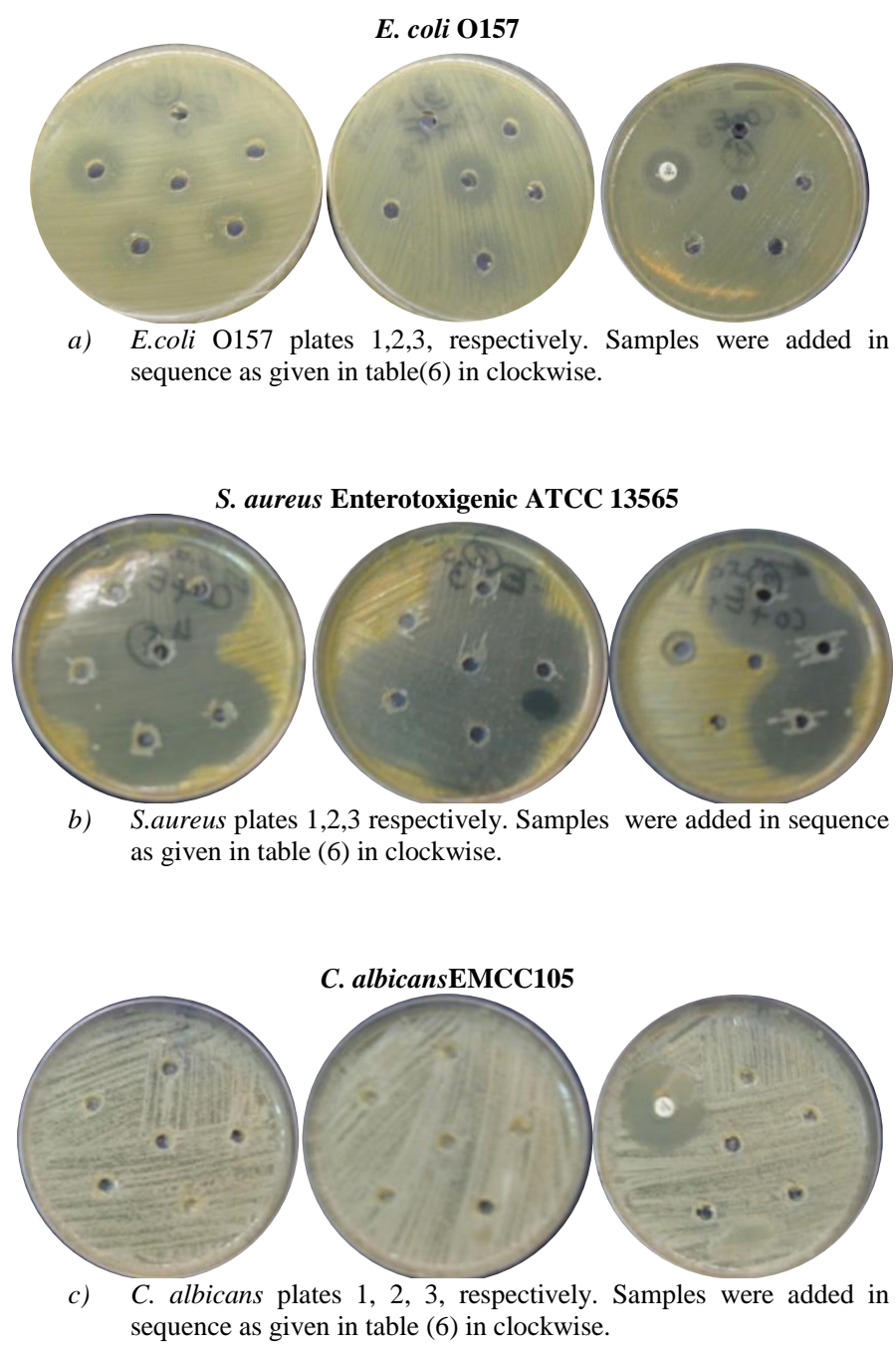

Fig. 12: Antimicrobial activity of 5- fluorouracil released from mPEG-b-PHAmPEG against a) E.coli, b) S.aureus c) C. albicans

\section{CONCLUSIONS}

1. A degradable triblock copolymer of type ABA was successfully synthesized, where A represents the hydrophilic segment that is methoxy-polyethylene glycol (mPEG) and B represents the hydrophobic segment that is polyhexylene adipate (PHA) and 3 different samples possessing different molecular weights are obtained.

2. Uni-modal nanoparticles were prepared from this block copolymer (mPEG-b-PHA-mPEG) using solvent displacement technique and used as a drug carrier for 5-FU.

3. Drug loading and entrapment efficiency were slightly influenced by the hydrophobic chain length.

4. A full drug release profile of 5-FU performed at different pHs and it was found to be higher in both acidic and alkaline media.

5. The sustained release of the active agent from the prepared copolymer showed that it can be a promising polymeric drug carrier for the antitumor drugs.

6. The cytotoxic activity of the released 5-fluorouracil indicated a sustained antiproliferative activity against the tested human liver cancer cell line as well as antimicrobial potency.

\section{ACKNOWLEDGEMENT}

Financial support and sponsorship: Yasser Assem would like to thank the In-house project office at National Research Centre for the financial support, as this work is a part of the indoor project No. 10070302

Conflict of Interests: There are no conflicts of interest.

\section{REFERENCES}

Babu V. R., Sairam M. ,Hosamani K. M., Aminabhavi T .M. Development of 5-Fluorouracil Loaded Poly (Acrylamide-comethylmethacrylate) Novel Core- Shell Microsheres: InVitro Release Studies. Int.J. Pharm, 2006; 325,55-62.

Barratt G. Colloidal drug carriers: achievements and perspectives, CMLS, Cell. Mol. Life Sci., 2003; 60, 21-37.

Chen C., Yu C.H., Cheng Y.C., Yu P.H.F., Cheung M.K. Biodegradable nanoparticles of amphiphilic triblock copolymers based on poly(3-hydroxybutyrate) and poly (ethylene glycol) as drug carriers., Biomaterials, 2006; 27, 4804-4814.

Cohen L., Rocco A. Study of the Crystallization Kinetics. Poly(ethylene oxide) and a blend of poly(ethylene oxide) and poly(bisphenol A-co-epichlorohydrin). Journal of Thermal Analysis and Calorimetry, 2000; 59, 625-632.

Couvreur P., Vauthier C. Nanotechnology: intelligent design to treat complex disease, Pharm. Res, 2006; 23, 1417-1450.

Dhamaniya, S.; Jacob, J. Synthesis and characterization of polyesters based on tartaric acid derivatives. Polymer, 2010; 51, 5392-99.

Ferruti, P.; Penco, M.; D'Addato, P.; Ranucci, E.; Deghenghi, R. 1995. Synthesis and properties of novel block copolymers containing poly(lactic-glycolic acid) and poly(ethyleneglycol) segments. Biomaterials 1995, 16, 1423-1428.

Fournier E., Passirani C., Vonarbourg A., Lemaire L., Colin N., Sagodira S., Menei P., Benoit J.P. Therapeutic Efficacy Study of Novel 5FU-Loaded PMM2.1.2- Based Microsphereson C6 Glioma. Int. J. Pharm, $2003 ; 268,31-35$.

Fras H L., Stana-Kleinschek K., Ribitsch V., Sfiligoj-Smole M., Kreze T. Quantitative determination of carboxyl groups in cellulose by complexometric titration, Lenzing. Ber., 2002; 81, 80-88. 
Fujimaki T. Processability and properties of aliphatic polyesters, 'BIONOLLE', synthesized by polycondensation reaction. Polymer Degradation and Stability, 1998; 59, 209-214.

Gallardo A., San Román J., Dijkstra P.J., Feijen J. Random polyester transesterification: prediction of molecular weight and MW distribution. Macromolecules, 1998; 31, 7187-7194.

Gaumet M., Vargas A., Gurny R., Delie F. Nanoparticles for drug delivery: the need for precision in reporting particle size parameters, Eur. J. Pharm. Biopharm. 2008; 69 1-9.

Ge H., Hu Y., Jiang X., Cheng D., Yuan Y., Bi H., Yang C. Preparation, characterization and drug release behaviors of drug Nimodipine-loaded poly( $\varepsilon$-caprolactone)-poly(ethylene oxide)-poly $(\varepsilon-$ caprolactone) amphiphilic triblock copolymer micelles, J. Pharm. Sci. 2002; 91 1463-1473

Gref R., Minamitake Y., Peracchia M. T., Trebetskoy V. S., Torchilin V. P., Langer R. Biodegradable long-circulating polymeric nanospheres, Science, 1994; 263, 1600-1603.

Gryparis C., Mattheolabakis G., Bikiaris D., Avgoustakis K. Effect of conditions of preparation on the size and encapsulation properties of PLGA-mPEG nanoparticles of Cisplatin. Drug Deliv, 2007; 14, 371-80.

Gudasi K.B., Vadavi R.S., Shelke N.B., Sairam M., Aminabhavi T. M. Synthesis and Characterization of Novel Polyorganophosphazanes Substituted with 4-Meth- oxybenzylamine and 4-Methoxyphenethylamine for In Vitro Release of Indomethacin and 5Fluorouracil, Reactive and Functional Polymers, 66,1149-1157.

Gupte A. and Ciftci K. Formulationand Characterization of Paclitaxel, 5-Fu and Paclitaxel+5-Fu Microspheres. Int. J. Pharm, 2004; 276: 93-106.

Han, S. I.; Yoo, Y.; Kim, D. K.; Im, S. S., 2004. Biodegradable Aliphatic Polyester Ionomers. Macromol.Biosci.2004, 4, 199-207.

He G., Ma L.L., Pan J., Venkatraman S. ABA and BAB type triblock copolymers of PEG and PLA: a comparative study of drug release properties and "stealth" particle characteristics, Int. J. Pharm. 2007; 334 $48-55$.

Helaly F. M., Elnashar D. E., Khalf A. I., Abdel Hamid H. F. S. I. Abd El-Moez S. I., Soliman A.M. Slow Release of 5-fluorouracil from Natural Polymeric Composites as Controlled Drug Delivery, Int. J. Pharm. Sci. Rev. Res., 2015; 30: 137-142.

Helaly F. M.,Khalf A. I.,Elnashar D. E., Abdel Hamid H. F., Soliman A. M. Bioassay and bioactivity of polymer as carrier for some active compounds such as anticancer drugs, Res Chem Intermed, 2014; 40:749-760

Hu Y., Xie J., Y.W. Tong, C.H. Wang. Effect of PEG conformation and particle size on the cellular uptake efficiency of nanoparticles with the HepG2 cells, J. Control. Release, 2007; 118, 7-17.

Huang L., Sui W., Wang Y., Jiao Q. Preparation of Chitosan/Chondroitin Sulfate Complex Microcapsules and Application in Controlled Releaseof5-Fluorouracil,CarbohydratePolymer, 2010; 80: 168173.

Jeyanthi R., Rao K. P. Release Characteristics of Bleomycin Mitomycin C and 5-Fluorouracil from Gelatin Microspheres, Int. J. Pharm, 1989; 55: 31-37.

Kataoka K., Harada A., Nagasaki Y. Block copolymer micelles for drug delivery: design, characterization and biological significance, Adv. Drug Deliv. Rev. 2001; 47: 113-131.

Menei P., Jadaud E., Faisant N., Boisdron-Celle M., Michalak S., Fournier D., Delhaye M., Benoit J.P. Stereotaxic Implantation of 5Fluorouracil-Releasing Microspheres in Malignant Glioma. Cancer, 2004; 100: 405-410.

Okada, M. Chemical syntheses of biodegradable polymers. Prog. Polym Sci., 2002; 27: 87-133.

Orive G., Gascon A.R., Hernandez R.M., Gil A.D., Perdaz J.L., 2004. Techniques: new approaches to the delivery of biopharmaceuticals, Trends Pharmacol. Sci., 25 382-387.

Owens III D.E., Peppas N.A. Opsonization, biodistribution and pharmacokinetics of polymeric nanoparticles. Int. J. Pharm. 2006; 307: 93-102.

Papadimitriou S., Bikiaris D. Novel self-assembled core-shell nanoparticles based on crystalline amorphous moieties of aliphatic copolyesters for efficient controlled drug release. J. Control. Release, 2009; 138177-184.

Pişkin Z., Kaitian X., DenkbaşE.B., Küçükyavuz Z. Novel PDLLA/PEG copolymer micelles as drug carriers, J. Biomat. Sci. Polym. Ed. 1995; 7: 359373.

Plage, B.; Schulten, H. R. Thermal degradation and massspectrometric fragmentation processes of polyesters studied by time/temperature-resolved pyrolysis-field ionization mass spectrometry, Macromolecules, 1990; 23: 2642-2648.

Rawat M., Singh D., Saraf S., Saraf S. Nanocarriers: promising vehicle for bioactive drugs, Biol. Pharm. Bull., 2006; 29: 1790-1798.

Ray, S. S.; Bousmina, M. Poly(butylene sucinate-coadipate)/montmorillonite nanocomposites: effect of organic modifier miscibility on structure, properties, and viscoelasticity. Polymer, 2005; 46: 12430-12439.

Reddy Seetharamareddy Harisha, Kallappa Mahadevappa Hosa mani, Rangappa Sang appa Keri, Namdev Shelke, Vijay Kumar Wadi, Tejaraj M. Aminabhavi. Controlled release of 5-flurouracil from biomedical polyurethanes) J. Chem. Sci. 2010; 122, 209-216.

Sastre R.S., Olmo R., Teijon C., Muniz E., Teijon J.M., Blanco M. D. 5-Fluorouracil Plasma Levelsand Biodegradation of Subcutaneously Injected Drug-Loaded Microspheres Prepared by SprayDrying Poly (D,L-lactide) and Poly (D,L-lactide-co-glycolide) Polymers, Int.J. Pharm, 2007; 338:180-190.

Sgouras D., Maragkoudakis P., Petraki K., Martinez-Gonzalez B., Eriotou E., Michopoulos S., Kalantzopoulos G., Tsakalidou E., Mentis A. In vitro and in vivo inhibition of Helicobacter pylori by Lactobacillus casei strain Shirota. Appl. Environ Microbiol, 2004; 70: 518-526.

Silva, V. P. R.; Silva, G. G.; Caliman, V.; Rieumont, J.; de Miranda-Pinto, C. O. B. Archanjo, B. S.; Neves, B. R. A. Morphology, crystalline structure and thermal properties of PEO/MEEP blends, European Polymer Journal, 2007; 43: 3283-3291.

Skehan P., Storeng R., Scudiero D., Monks A., McMahon J., Vistica D., Warren J.T., Bokesch H., Kenney S., Boyd M. J Natl, Cancer Inst., 1990; 82, 1107-1112.

Soccio, M.; Lotti, N.; Finelli, L.; Gazzano, M.; Munari, A. Aliphatic poly(propylene dicarboxylate)s: Effect of chain length on thermal properties and crystallization kinetics, Polymer, 2007; 48: 31253136 .

Stolnik S., Illum L., Davis S.S. Long circulating microparticulate drug carriers, Adv. Drug Deliv. Rev., 1995; 16: 195-214.

Sun, J.; Bubel, K.; Chen, F.; Kissel, T.; Agarwal, S.; Greiner, A. Nanofibers by Green Electrospinning of Aqueous Suspensions of Biodegradable Block Copolyesters for Applications in Medicine, Pharmacy and Agriculture. Macromol. Rapid Commun., 2010; 31: 20772083.

Torchilin V. P. PEG-based micelles as carriers of contrast agents for different imaging modalities, Adv. Drug Deliv. Rev. 2002; 54: 235-252.

Torchilin V. P., Trubetskoy V. S. Which polymers can make nanoparticulate drug carriers long-circulating? Adv. Drug Deliv. Rev., 1995b ; 16: 141-155.

Vassiliou A. A., Papadimitriou S. A., Bikiaris D. N., Mattheolabakis G., Avgoustakis K. Facile synthesis of polyester-PEG triblock copolymers and preparation of amphiphilic nanoparticles as drug carriers. J. Control. Release, 2010; 148: 388-395.

Wang Q., Du Y., Fan L. Properties of Chitosan/Poly (vinylalcohol) Films for Drug-Controlled Release. J. Appl. Polym. Sci., 2005; 96,808-813.

Wiart, C. Goniothalamus species: A source of drug for the treatment of cancers and bactericidal infections. Oxford J Med; 2007; 4: 299-311.

Winzenburg, G.; Schmidt, C.; Fuchs, S.; Kissel, T. Biodegradable polymers and their potential use in parenteral veterinary drug delivery systems. Adv. Drug Deliv. Rev., 2004; 56: 1453-1466.

Yang, J.; Pan, P.; Dong, T.; Inoue, Y. Crystallization kinetics and crystalline structure of biodegradable Poly(ethylene adipate). Polymer, 2010; 51: 807-815. 
Yasser Assem. 2011. Biodegradable Amphiphilic Block Copolymers: Synthesis, Characterization and Properties Evaluation. $\mathrm{PhD}$ Thesis, Marburg, Germany. Available at: http://archiv.ub.unimarburg.de/ubfind/Record/urn:nbn:de:hebis:04-z2011-0603.

Zhang L., Hu Y., Jiang X., Yang C., Lu W., Yang Y.H. Camptothecin derivative-loaded poly(caprolactone-co-lactide)-b-PEG-bpoly(caprolactone-co-lactide) nanoparticles and their biodistribution in mice. J. Control. Release, 2004; 96: 135-148.

How to cite this article:

Assem Y, Helaly FM, Soliman A, Abdelmoez S. Synthesis of aliphatic biodegradable polyesters nanoparticles as drug carrier for cancer treatment. J App Pharm Sci, 2016; 6 (12): 032-041. 